\title{
Nutrient Adequacy and Incidence of Common Complications in Women on ART in Manipur State, India.
}

\author{
Kshetrimayum Bimolata Devi ${ }^{1}$, Dr. M. Amuba Singh ${ }^{2}$, Dr. Th. Bhimo Singh ${ }^{3}$. \\ ${ }^{I}$ Ph. D. Scholar, Dept of Biochemistry, Regional Institute of Medical Sciences (RIMS), Imphal, Manipur State, \\ India. \\ ${ }^{2}$ Professor \& Head,Department of Biochemistry. RIMS, Imphal Manipur State, India. \\ ${ }^{3}$ Professor, Department of Medicine, RIMS, Imphal Manipur State, India.
}

\begin{abstract}
A cross sectional study to study the food intake, nutrient adequacy and incidence of common complications \& adverse events in Manipur state, India, was carried out on 442 women on ART in 2 hospitals, RIMS \& JNIMS from April, 2009-October 2012. Anthropometric assessments, diet survey by 24 hours recall method, \& hemoglobin estimation was done. Average mean age of the women was 37.62 years. $55.7 \%$ consisted of widows, $68.8 \%$ had monthly income less than Rs. 5000 per month, $86.2 \%$ of the women got the virus from their husbands who were ex-IDUs. Mean intake of cereals, roots \& tubers were significantly higher when compared against the recommended levels while intake of all other remaining items was significantly lower. Mean daily intake of protein, fat, calcium and vitamin-C were more than RDA whereas the intake of energy, iron, carotene, thiamin, riboflavin \& niacin were less. Average BMI was 21.04, average W: $H$ was 0.84 . Mean hemoglobin was $10.36 \mathrm{~g} / \mathrm{dl}, 55.9 \%$ had mild anemia. There were 12 cases of HCV, 4 cases of HBV, 15 cases of TB. Most recorded discomfort was anorexia (43 cases) and heartburn/ bloating (33 cases). Study suggested compulsory diet counseling with nutritional supplementation \& monetary assistance, to have important therapeutic benefits in AIDS patients as an adjuvant treatment in combination with antiretroviral therapy.
\end{abstract}

Keywords: HIV/ AIDS, RIMS, JNIMS, ART, NACO, NIN, ICMR, MACS.

\section{Introduction}

Nutritious food is one of the most powerful weapons available for fighting the often-calamitous effects of AIDS. HIV infected individuals can manage his/her symptoms, boost immune responses and improve adherence and response to Anti Retroviral Therapy (ART) and other medical treatment. Good nutrition can strengthen the immune system and increase resistance to opportunistic infections (OI) related to HIV/AIDS whereas poor nutrition has the opposite effect ${ }^{[1]}$.

As per the latest statistics of UNAIDS on World AIDS Day report $2012^{[2]}$, worldwide, women constitute more than half of all people living with HIV/AIDS. Among young people aged 15-24, the HIV prevalence rate for young women twice is that of young men.

The American National Institute of Health $(\mathrm{NIH})$ and certain other organizations like Food \& Drug Administration (FDA), World Health Organization (WHO), National Aids Control Organization (NACO), etc. recommend offering antiretroviral treatment to all patients with AIDS.

Highly Active Antiretroviral Therapy (HAART), introduced in 1996 is the recommended treatment for HIV infection which combines three or more anti-HIV medications in a daily regimen. Anti-HIV medications are used to control the reproduction of the virus and to slow the progression of HIV-related disease ${ }^{[3]}$. Since the appearance of HAART, a lower incidence of malnutrition and an improvement of the survival \& immunological functions of infected patients were reported ${ }^{[4]}$. Anti retroviral therapy (ART) offers new hope for effective treatments, but even the most promising combination therapies have side effects, which can be reduced by proper nutrition ${ }^{[5]}$.

In developing countries, infections in females are growing more rapid than in males, with women of childbearing age the fastest growing subgroup of the HIV infected population. The greater risk for HIV infection amongst women is caused by biologic, social, economic, and cultural factors ${ }^{[6]}$.

1.1 HIV/AIDS in India: India is one of the largest and most populated countries in the world, with over one billion inhabitants. It is also home to perhaps one of every eight people with HIV infection ${ }^{[7]}$. India has the second largest number of HIV infected people after South Africa; the estimate is about 5.8 million persons as per report of National Aids Control Organization (NACO) ${ }^{[8]}$.

1.2 HIV in Manipur: Of India's 35 states and territories, 6 have very high prevalence rates (Andhra Pradesh, Karnataka, Maharashtra, Manipur, Nagaland and Tamil Nadu). Manipur, a small state in the northeast region of India, is a state with the highest concentration of HIV/AIDs in India and HIV/AIDS has emerged as a new and serious public health emergency. As of January 2011, a total 31256 positive cases were found. Out of these 10109 are female cases. Sero-positivity rate per 100 samples is $8.0^{[9]}$. 


\section{Materials \& Methods}

A cross sectional study on 442 HIV positive women on ART was carried out in the 2 hospitals in Imphal City: Regional Institute of Medical Sciences (RIMS), \& Jawaharlal Nehru Institute of Medical Sciences (JNIMS), from April, 2009-October 2012. Women in the reproductive age group, willing to participate in the study and cases on ART who had completed at least 6 months of therapy were included. Those under 15 years of age, who refused to give consent, seriously ill and bedridden patients.

Anthropometric assessment like measurement of height, weight, Body Mass Index (BMI), circumference of waist \& hip were recorded, computed and analyzed. Diet survey by 24 hours recall method was adopted. Nutrient intakes were calculated using Indian Food Composition Tables then compared to recommended levels formulated by B.V. Gopalan et al, National Institute of Nutrition (NIN), Indian Council of Medical Research (ICMR) ${ }^{[10]}$, to check their nutrient adequacy or deficiency in their daily meals. Biochemical assessment by estimation of hemoglobin was also done. Major study and analysis of collected data, analysis of diet surveys, blood samples etc. were done in the department of Biochemistry, RIMS, Imphal.

Ethical approval and clearance was sought from Institutional Ethical Committee, RIMS. Approval and Clearance also sought from Project Director, Manipur AIDS Control Society (MACS). Statistical data processing and analysis was performed through SPSS version 21.

\section{Aims \& Objectives}

To study the food intake, nutrient adequacy and incidence of common complications and adverse events in women on Antiretroviral Therapy in Manipur State, India.

\section{Results}

4.1 Background: Average mean age of the women in the sample population was 37.62 years. More than half of the women in the sample population $(55.7 \%)$ consisted of widows. Majority of the respondents $(57.9 \%)$ were Hindus followed by 37.8 per cent Christians, whereas only 4.3 per cent were Muslims. educational level of the respondents ranged from illiterate and primary level to postgraduate levels. majority were housewives (31.9\%), More than half of the respondents had monthly income less than Rs. 5000 per month (68.8\%). Maximum (86.2\%) of the women in the sample population got the virus from their husbands who had previously been Intravenous drug users. Analysis on meals and meal patterns of the women showed that number of meals consumed in a day ranged from 2-4 times with some rarely having a snack at afternoon tea time.

4.2: Food Intake: The mean food composition of the women were computed and compared against the recommended balanced diet as suggested by the ICMR/NIN. Mean intake of cereals, roots \& tubers were significantly higher when compared against the recommended levels while intake of all other remaining items was significantly lower.

Table: 1. Composition of Diet

\begin{tabular}{|c|c|c|c|c|c|c|}
\hline Foods items & $\begin{array}{l}\text { Balanced } \\
\text { diet }\end{array}$ & $\begin{array}{l}\text { Mean } \pm \text { SD of } \\
\text { intake }\end{array}$ & Excess/deficit & t-value & $\overline{d f}$ & P-value \\
\hline Cereals & 300 & $490.29 \pm 55.59$ & 190.29 & 71.961 & 441 & $<.001$ \\
\hline Pulses & 50 & $25.26 \pm 25.11$ & -24.74 & 20.712 & 441 & $<.001$ \\
\hline$\overline{G L V}$ & 100 & $44.98 \pm 38.01$ & -55.02 & 30.432 & 441 & $<.001$ \\
\hline $\begin{array}{ll}\text { Roots } & \& \\
\text { Tubers } & \end{array}$ & 75 & $114.03 \pm 116.01$ & 39.02 & 7.073 & 441 & $<.001$ \\
\hline $\begin{array}{l}\text { Other } \\
\text { vegetables }\end{array}$ & 75 & $48.14 \pm 49.37$ & -26.85 & 11.436 & 441 & $<.001$ \\
\hline Nuts & 30 & $.70 \pm 4.87$ & -29.29 & 126.341 & 441 & $<.001$ \\
\hline Fruits & 60 & $20.75 \pm 28.15$ & -39.25 & 29.308 & 441 & $<.001$ \\
\hline Meat + fish & 60 & $7.77 \pm 26.17$ & -52.22 & 41.958 & 441 & $<.001$ \\
\hline Eggs & 30 & $1.58 \pm 9.29$ & -28.41 & 64.281 & 441 & $<.001$ \\
\hline Milk & 250 & $33.39 \pm 73.73$ & -216.60 & 61.757 & 441 & $<.001$ \\
\hline Oils & 40 & $17.93 \pm 10.10$ & -22.07 & 45.918 & 441 & $<.001$ \\
\hline Sugars & 30 & $10.64 \pm 8.98$ & -19.36 & 45.311 & 441 & $<.001$ \\
\hline
\end{tabular}


Nutrient Adequacy and Incidence of Common Complications in Women on ART in Manipur State,

4.3 Nutrient Adequacy: To assess discrepancy between nutrient intake with recommended dietary allowance, independent $\mathrm{t}$-test was applied and findings are set forth in table- 2 .The mean daily intake of protein, fat; calcium and vitamin-C were more than the recommended levels prescribed by ICMR/NIN, India, whereas the intake of energy, iron, carotene, thiamin, riboflavin \& niacin were less than that of the recommend levels. The excess in intake of protein, fat and vitamin- $\mathrm{C}$ was highly significant $(\mathrm{P}<0.001)$ while excess in intake of calcium was not significant statistically $(\mathrm{P}=0.257)$. It is worthwhile to mention that the deficiency in intake of iron, carotene, thiamin, riboflavin and niacin were found highly significant $(\mathrm{P}<0.001)$ than the recommend allowance except for energy $(\mathrm{P}=0.031)$ which was just significant at $5 \%$ probability level.

Table: 2. Nutrient intake

\begin{tabular}{|c|c|c|c|c|c|c|}
\hline Nutrients & $\begin{array}{l}\text { *Recommended } \\
\text { Dietary } \\
\text { Allowance(RDA) }\end{array}$ & $\begin{array}{l}\begin{array}{l}\text { Mean } \\
\text { intake } \\
(\mathrm{n}=442)\end{array} \\
\end{array}$ & Excess/deficit & $\mathrm{t}$-value & $\overline{\mathrm{df}}$ & $\mathrm{P}$-value \\
\hline Protein $(\mathrm{g})$ & 50 & $54.27 \pm 10.63$ & 4.27 & 8.446 & 441 & $<0.001$ \\
\hline Fat $(\mathrm{g})$ & 20 & $25.52 \pm 10.77$ & 5.52 & 10.775 & 441 & $<0.001$ \\
\hline Energy(k.cal) & 2225 & $2202.92 \pm 213.94$ & -22.08 & -2.170 & 441 & 0.031 \\
\hline Calcium(mg) & 400 & $416.80 \pm 311.48$ & 16.8 & 1.134 & 441 & 0.257 \\
\hline Iron(mg) & 30 & $11.68 \pm 6.45$ & -18.32 & -59.611 & 441 & $<0.001$ \\
\hline Carotene $(\mu \mathrm{g})$ & 2400 & $1794.66 \pm 1081.13$ & -605.34 & -11.771 & 441 & $<0.001$ \\
\hline Thiamine(mg) & 1.1 & $0.70 \pm .018$ & -0.4 & -44.501 & 441 & $<0.001$ \\
\hline Riboflavin(mg) & 1.3 & $0.75 \pm 0.45$ & -0.55 & -24.853 & 441 & $<0.001$ \\
\hline Niacin(mg) & 14 & $4.91 \pm 2.47$ & -9.09 & -77.252 & 441 & $<0.001$ \\
\hline Vitamin-C(mg) & 40 & $136.88 \pm 54.46$ & 96.88 & 37.400 & 441 & $<0.001$ \\
\hline
\end{tabular}

Anthropometric profile: Mean height of the women was $154.74 \mathrm{~cm}$, mean weight was $49.66 \mathrm{~kg}$, average BMI was 21.04. Majority of the women (82.8\%) were within the normal range of BMI of 18-25. Average waist circumference was 30.14 inches; average hip circumference was 36 inches. Average waist to hip (W: H) ratio was 0.84 . Majority (45.9\%) had ratios ranging from 0.81-0.85 depicting moderate risk to health. Measurement of mid upper arm circumference show that 99.5 per cent of the women had circumferences less than $160 \mathrm{~mm}$ and were termed to be suffering from severe under nutrition ${ }^{[11]}$.

Biochemical assessment: The degrees of anemia were classified according to World Health organization (WHO, 1989). Moderate anemia when hemoglobin values are $7-9.9 \mathrm{mg} \%$, mild anemia $(10-11 \mathrm{mg}$ $\%)$, and within Normal range (11-12mg \%). Mean hemoglobin value was $10.36 \mathrm{~g} / \mathrm{dl}$, majority of the women suffer from mild anemia (55.9\%). Mean present CD4 was 418.04 (highest was 1122).

Anti-retroviral therapy: Maximum (47.7\%) were found to be on the combination of Stavudine (STV) \& Lamivudine (LMV) with Nevirapine (NVP). 97.52 per cent of the women were on $1^{\text {st }}$ line regimen, ten women $(2.3 \%)$ were already on the second line regimen.

4.4 common Complications: There were 12 cases of HCV in the study population, 4 cases of HBV, 15 cases of TB (post treatment), 2 diabetics, 2 cases of gall bladder problems (post-operation) etc. There were 6 cases with pronounced lipo atrophy, 2 with cryptococcal meningitis, 2 cases with yellow skin which may be symptomatic of jaundice. There was a case of swelling at right side of neck and one case reporting to have blood in stool, while 2 women in the sample were pregnant (Table-3).

Table-3

\begin{tabular}{|l|l|}
\hline Complications \& associated symptoms & cases \\
\hline HCV & 12 \\
\hline HBV & 4 \\
\hline TB & 15 \\
\hline Diabetic & 2 \\
\hline Operated(gall-stones) & 3 \\
\hline Lipo atrophy & 6 \\
\hline Cryptococcal meningitis & 2 \\
\hline Often blood in stools & 1 \\
\hline Swelling at right neck & 1 \\
\hline Jaundice/yellow skin & 2 \\
\hline Pregnant & 2 \\
\hline
\end{tabular}


Nutrient Adequacy and Incidence of Common Complications in Women on ART in Manipur State,

\subsection{Adverse events:}

Table:4- Adverse events

\begin{tabular}{|l|l|}
\hline Adverse events & $\mathrm{n}$ \\
\hline No complaints & $132(29.86 \%)$ \\
\hline Fever & 10 \\
\hline Anorexia & 43 \\
\hline Diarrhea & 11 \\
\hline Constipation & 6 \\
\hline Fatigue/lethargy & 26 \\
\hline Nausea/vomiting & 11 \\
\hline Headache & 13 \\
\hline Cough & 22 \\
\hline Mouth sores & 13 \\
\hline Numbness/tingling at hands or feet & 20 \\
\hline Insomnia & 26 \\
\hline Eye problems/blurring vision & 23 \\
\hline Heartburn/bloating & 33 \\
\hline Giddiness/drowsiness & 28 \\
\hline Skin allergies/rashes & 26 \\
\hline Shortness of breath & 6 \\
\hline Skin allergies/rashes & 26 \\
\hline Hypertension & 11 \\
\hline Problem with monthly cycle & 3 \\
\hline Foul smelling mouth & 5 \\
\hline
\end{tabular}

Only 29.86 per cent of the women in the study population reported to have no complaints at the time of data collection. Most recorded discomfort was Anorexia (43 cases), followed by heartburn/ bloating (33 cases), then giddiness/drowsiness (28), giddiness/drowsiness (28), insomnia (26), fatigue/ lethargy (26), rashes/skin allergies (26) etc. Others were fever (10 cases), diarrhea (11), nausea (11), headache (13), cough (22), mouth sores(13), tingling/numbness at hands or feet (20), eye problems and blurring vision (23), and others comprising of hypertension, problem with monthly cycle, foul smelling breath etc.(Table-4).

\section{Discussion}

The data included the people coming from different parts of Manipur other than from the main city so the findings are relevant to the whole state of Manipur. Donor countries pour billions of dollars into anti retroviral and other medications to counter the growing impact of AIDS in Africa, Asia and Latin America with barely a thought of nutrition ${ }^{[12]}$. World Food Programme estimates that people enrolled in ART needs some kind of nutritional support as part of the essential package of care for PLWHA.

Average mean age of the women in the sample population was 37.62 years. A mean age of 37 years and 36 years was also found in other studies of AIDS patients ${ }^{[13]}{ }^{[14]}$. More than half of the respondents had monthly income less than Rs. 5000 per month (68.8\%). Majority with a monthly income of less than 3000/m was also observed among HIV infected IDUs in Chennai ${ }^{[15]}$.

In the study, tea was a frequently mentioned beverage, especially in morning so as to take the morning medications. But some women reported taking tea and the medicine but without any solids. Rice was the main food item consumed at lunch and dinner. Consumption of sugars was limited to that taken with tea. Less consumption of milk and dry fruits was due to financial constraints. It was also observed that the women who come to the ART centre to take their monthly medicines by bus from some far districts start from home early without food so as to reach the centre on time but before closing. This system may have aggravated the stomach ulcer which was reported by many women while collecting data on common health complaints.

Intake of energy, iron, carotene, thiamin, riboflavin \& niacin were less than that of the recommend levels. Significant low nutrient intake was also observed by in a study of nutritional status of HIV infected patients in N-India. In the study, the main sources of calories in the diet were rice and roots $\&$ tubers. Consumption of eggs, milk, nuts and sugars were less which may be the reason for the low calorie in the diet. The intake of vitamin $\mathrm{C}$ was far above the requirements. It might be due to the fact that the content of vitamin $\mathrm{C}$ was very high in those selected fruits although the fruit consumption was low. Example: citrus fruits, banana, tomatoes etc. The type of leafy vegetable eaten like cabbage, spinach etc may also have influenced the dietary vitamin $\mathrm{C}$ content. High calcium in their diet may also be due to their selection of fishes which have high calcium content even though amount of consumption was less.

Average BMI in the study was 21.04, and average $\mathrm{W}$ : $\mathrm{H}$ ratio was 0.84 . Waist to Hip ratio of more or greater than 0.8 was observed in a study in South African women with HIV with a median BMI of $24.4 \mathrm{~kg} / \mathrm{m}^{2 .[17]}$. Mean hemoglobin value in the study was $10.36 \mathrm{~g} / \mathrm{dl}$. Anemia is more common and more severe with advanced HIV disease progression but studies disagree on whether this is principally due to iron deficiency anemia or to anemia of chronic disease ${ }^{[18]}$. Mean baseline CD4 in the present study was 144.24 . Mean baseline 
Nutrient Adequacy and Incidence of Common Complications in Women on ART in Manipur State,

$\mathrm{CD} 4$ of $112 \pm 60$ was also observed in another study of Correlation between baseline CD4 ${ }^{+}$T-Lymphocyte count and plasma viral load in AIDS patients and their early clinical and immunological response to HAART ${ }^{[19]}$.

In the present study, there were 12 cases of $\mathrm{HCV}, 4$ cases of $\mathrm{HBV}, 15$ cases of TB, 6 cases with pronounced lipo atrophy. TB and Hepatitis $\mathrm{C}$ are the 2 most common co-infections in HIV ${ }^{[20]}$. Most recorded adverse event in this study was anorexia (43 cases), followed by heartburn/ bloating (33 cases). Upper abdominal pain, heartburn, bloating as the most common GI symptoms, while anorexia, nausea, vomiting were more frequent opportunistic infection (OI) was also reported ${ }^{[21]}$. Nausea and frequent vomiting may result from drug therapy used to treat HIV/AIDS or opportunistic infections. Besides reduced appetite loss, nausea also leads to mal absorption in these patients ${ }^{[22]}$.

Most common adverse reaction is peripheral neuropathy and lipodystrophy in the stavudine group. Adverse effects of antiretroviral drugs vary by drug, by ethnicity, by individual, and by interaction with other drugs, including alcohol. Hypersensitivity to some drugs may also occur in some individuals ${ }^{[23]}$. Availability of ART appeared like a boon but it had its associated discomforts and complications leading to reduced food intake, which again resulted in low nutritional status, low hemoglobin profile and abnormalities in other biochemical test results.

Manipur is a state with the highest concentration of HIV/AIDS in India, a majority of them IDUs. Interventions have focused on the IDUs and but have neglected their spouses, sexual partners and children. There have been instances where programmes have been suspended for sometime or abandoned together for lack of funds, which does not bode well for people who are living with HIV/AIDS ${ }^{[24]}$.

\section{Summary \& Conclusion}

The present study is the first study of its type conducted in Manipur state, and in the north-eastern part of India. This study highlights the problems faced by the HIV infected women regarding their overall nutritional status and health in depth.

Following certain ethical issues to guard the privacy of the women, method of 24-hour Recall diet survey was adopted. There may be certain bias in answering the questionnaire. Certain food intakes \& other information may be over or under presented, which may have resulted in the less significant pictures in certain expected areas. Use of Actual food weighment method would've revealed truer picture and realistic results. The present study was a cross-sectional study. A longitudinal study of HIV patients on ART after nutritional supplementation with proper nutrition education could provide more informative results.

It is strongly suggested that, compulsory diet counseling along with nutritional supplementation, or some sort of monetary assistance for the low income infected women, will have important therapeutic benefits in AIDS patients as an adjuvant treatment in combination with antiretroviral therapy. Such a study with good follow-up plan can provide much knowledge of this disease and will help formulation of need based government policies \& programmes and effective strategies to solve the problems associated with overall health \& wellbeing of people living with HIV/AIDS.

\section{Acknowledgements}

The authors are thankful to the Director, RIMS, Imphal and the then HOD, department of Biochemistry, RIMS, for allowing to carry out the study in the Institute. The authors also thank the then Project Director MACS, and the Nodal officers of the ART centres of RIMS \& JNIMS. A deep sense of gratitude is expressed to the women on ART in the study without whom the study would not have been possible.

\section{References}

[1] A. Shubhangini Joshi, Nutrition in HIV and AIDS in Nutrition and Dietetics, (Tata McGraw Hill Education Pvt. Ltd, 2010), 357-369.

[2] UNAIDS (2012). Global report on the AIDS epidemic. Author.

[3] HIVand ItsTreatment_cbrochure_en Accessed: April 22, 2011.

[4] M. Stambulin, S. Feliu and N.H. Slobodianik, Nutritional status in patients with HIV infection and AIDS. British J Nutr. 98 (2007), suppl 1:S140-S143.

[5] Life(2000)*Dietary mgt of aids-Accessed: Saturday, October 13, 2007.

[6] E.G. Piwoz \& E.A. Preble, HIV/AIDS and nutrition: a review of the literature and recommendations for nutritional care and support in Sub-Saharan Africa. Washington DC: Academy for Educational Development, 2000.

[7] Suniti Solomon and Aylur Kailasam Ganesh, , Special Contribution- HIV in India, Topics in HIV Medicine, IAS (USA) Vol 10, Issue 3, Jul-Aug 2002, p 19-24.

[8] NACO,2012.

[9] MACS, Epidemiological Analysis of HIV/AIDS in Manipur, Imphal, Nov- 2012. 
Nutrient Adequacy and Incidence of Common Complications in Women on ART in Manipur State,

[10] C. Gopalan, B.V. Rama Sastri \& S.C. Balasubramanian, Nutritive Value of Indian Foods. Revised \& updated by: B.S. Narasinga Rao,Y.G. Deosthale \& K.C. Pant, National Institute of Nutrition, (Indian Council of Medical Research, Hyderabad,India, 2004).

[11] www.unsystem.org/SCN/archives/adults/ch06.htm

[12] AIDS-Asia, Jan-Apr, 2007.

[13] F. Visnegarwala, L. Chen, S. Raghvan, E. Tedaldi Prevalence of Diabetes mellitus \& dislipidemia among antroviral naïve patients co infected with Hepatitis $\mathrm{C}$ virus(HCV) and HIV-1 compared to patients without co-infection. J. of Infection, 4 (50) (2005),331-337.

[14] P. Palaisamy, B. Govindaswamy, S. Ganeshan and D. Ayyaswamy, Changes in CD4 cell count, lipid profile and liver enzymes in HIV infection and AIDS patients, J. Appl. Biomed; 6(2008): 139-145.

[15] S S Solomon,C S Hawcroft, P Narasimhan, R Subbaraman,A K Srikishan,a J Cecelia, M Sureshkumar, Suniti Solomom, J E Gallant \& D D Celentano, Comorbiditis among HIV-infected Injection Drug Users in Chennai, India. Indian J Med Re 127, May 2008,pp 447-452.

[16] Sunita et al, Assessment of Nutritional status of HIV infected patients at a tertiary centre in North India. Tropical Doctor, Royal society of Medicine Press, 37; (2007), 167-169.

[17] Zorada Hattingh, The Health and Nutritional Status of HIV positive women in Mangaung, , doctoral diss., University of Free state, 2005, p 255-56, 281-85.

[18] N.R. Van den Brock, Etiology of anemia in pregnancy in south Malawi. Am J Clin Nutr. 72(suppl), 2000, 247S-56S

[19] H. Gautam, P Bhalla, S Saini, R Dewan: Correlation between baseline CD4 ${ }^{+}$T-Lymphocyte count and plasma viral load in AIDS patients and their early clinical and immunological response to HAART: A Preliminary study. Indian Journal of Medical Microbiology,(2008) 26(3):256-258.

[20] C Padmapriyadarshini, J Chandrabose, L Victor, L E Hanna, N Arunkumar, S Swaminathan, Hepatitis B or $\mathrm{C}$ co-infection in individuals infected with human immunodeficiency virus and effect of antituberculosis drugs on liver function, J Postgrad Med, April(2006), vol 52, Issue 2, p 92-96. Downloaded from www.jpgonline.com. Accessed: Thursday, May28, 2009.

[21] M.A. Olomos, Endoscopic approach in HIV patients with upper G-I symptoms, 2004.

[22] United States Agency for International Development (USAID), HIV/AIDS: a guide for nutrition, care and support. Washington DC, 2001

[23] Antiretroviral drug, Wikipedia, the free encyclopedia, Accessed: Friday April 22, 2011.

[24] Chitra Ahanthem, HIV/AIDS in Manipur: The need to focus on women, downloaded from www.hivaidsonline.in, Accessed: 23 August, 2010. 